\title{
Hormone-dependent shrinkage of a sphenoid wing meningioma after pregnancy: case report
}

\author{
Johannes Kerschbaumer, MD, ${ }^{1}$ Christian F. Freyschlag, MD, ${ }^{1}$ Günter Stockhammer, MD, ${ }^{2}$ \\ Susanne Taucher, MD, ${ }^{3}$ Hans Maier, MD, ${ }^{4}$ Claudius Thomé, MD, ${ }^{1}$ and \\ Marcel Seiz-Rosenhagen, MD'
}

Departments of ${ }^{1}$ Neurosurgery, ${ }^{2}$ Neurology, ${ }^{3}$ Obstetrics and Gynecology, and ${ }^{4}$ Pathology, Medical University of Innsbruck, Austria

\begin{abstract}
Meningiomas are known to be associated with female sex hormones. Worsening neurological symptoms or newly diagnosed meningiomas have been described in the context of elevated levels of sex hormones, for example, in pregnancy. To the authors' knowledge, tumor shrinkage after the normalization of hormones has not been described, even if it is known that neurological deficits due to meningioma compression may improve after giving birth.
\end{abstract}

A 32-year-old female patient presented with severe headache and vision disturbances at the end of her second pregnancy. Magnetic resonance imaging revealed an extended mass at the lateral left-sided sphenoid wing that was suspected to be a meningioma. After delivery, the patient's symptoms improved, and MRI obtained 2 months postpartum showed significant shrinkage of the lesion.

Significant tumor shrinkage can occur after pregnancy. Thus, repeat imaging is indicated in these patients. http://thejns.org/doi/abs/10.3171/2014.12.JNS142112

KEY WORDS meningioma; shrinkage; pregnancy; progesterone; hormone dependent; oncology

$\mathrm{M}$ ENINGIOMAS compose the most frequently reported intracranial tumors with an incidence rate of $10 \%-20 \%$ of all intracranial neoplasms, ${ }^{6}$ although their etiology is still unclear. Several risk factors have been described for meningiomas arising from arachnoidal cap cells. Previous radiation therapy and genetic disorders (for example, neurofibromatosis Type 2) increase the prevalence of intracranial meningiomas. Furthermore, sex hormones in general and female sex hormones especially ${ }^{7}$ promote meningioma development.

Pregnancy itself does not increase the incidence of intracranial neoplasms. ${ }^{22}$ However, a worsening of symptoms by the accelerated growth of meningiomas during pregnancy has been described..$^{16,17,19}$ The underlying mechanism for this growth may consist of elevated serum estrogen and progesterone levels in pregnant patients. ${ }^{22,30,32}$ The diagnosis of a symptomatic intracranial meningioma during pregnancy presents a challenge for both gynecologists and neurosurgeons. If there is a need for surgical intervention, ${ }^{25}$ potential risks will involve not only the patient her- self but also the unborn child. Therefore the management and finally the treatment of meningiomas during pregnancy require close interdisciplinary cooperation among gynecologists, neurologists, and neurosurgeons. ${ }^{18} \mathrm{We}$ present a case of significant postpartum tumor shrinkage of a sphenoid wing meningioma diagnosed during pregnancy. Immunohistochemical analysis of the tumor specimen demonstrated an overexpression of progesterone, which may explain the hormone-dependent growth and shrinkage documented by MRI.

\section{Case Report}

History and Examination

A 32-year-old female (gravida 2, para 1) presented to the Department of Obstetrics and Gynecology at the Medical University of Innsbruck at gestation week $39+2$ with prolonged and severe headache combined with vomiting, vision disturbance, and persistent tearing from her left eye. Migraines had been diagnosed in her teenage years, and

SUBMITTED September 9, 2014. ACCEPTED December 18, 2014.

INCLUDE WHEN CITING Published online July 10, 2015; DOI: 10.3171/2014.12.JNS142112.

DISCLOSURE The authors report no conflict of interest concerning the materials or methods used in this study or the findings specified in this paper. 
during her first pregnancy she had experienced worsening of her migraines with attacks every 2-3 weeks. Ultrasonography studies of the fetus showed no abnormalities, and there was no evidence of HELLP syndrome in the patient's serum. The patient was also seen by neurology and ophthalmology, and migraine attack with cluster headache was diagnosed. To exclude a vascular pathology as the cause of her symptoms, standard cranial MRI (without contrast agent; T1- and T2-weighted and time-offlight angiography) was performed. A left-sided lesion (53 $\times 66 \mathrm{~mm}, 53.1 \mathrm{~cm}^{3}$ ) with local mass effect and perifocal edema was detected and suspicious for a lateral sphenoid wing meningioma (Fig. 1). After the tentative diagnosis, an uneventful cesarean section was performed because of a term unborn (no retardation in growth or organ formation) in ultrasonography diagnostics. Delivery was followed by Gd-enhanced MRI, which showed homogeneous enhancement of contrast agent, reinforcing the suspected diagnosis.

Postpartum, the patient still demonstrated no neurological deficit and no evidence of epileptic seizures under lowdose steroid therapy; thus, the resection was postponed for elective surgery 2 months after delivery. Magnetic resonance imaging was repeated before the scheduled surgery, revealing significant mass reduction (50\%) of the initial tumor $\left(30 \times 35 \mathrm{~mm}, 27.6 \mathrm{~cm}^{3}\right.$; Fig. 1). Options were discussed with the patient.

\section{Operation}

Microsurgical resection was uneventfully performed via a left frontotemporal craniotomy without complications. A complete resection could be achieved by excising the basal dura mater and drilling the hyperostotic areas of the lateral sphenoid with a high-speed bur.

\section{Postoperative Course}

Except for a single epileptic seizure 1 day after surgery, the patient's course was uneventful. Anticonvulsive treatment was administered for 3 months, so breastfeeding had to be discontinued. Postoperative imaging showed complete resection of the tumor.

\section{Histopathological Workup}

Histopathological workup was performed using readyto-use antibodies against the estrogen receptor and the progesterone receptor (both Ventana). It revealed the diagnosis of a microcystic meningioma (WHO Grade I) with progesterone receptor expression over $90 \%$ (Fig. 2). The tumor showed no expression of the estrogen receptor.

\section{Discussion}

In WHO Grade I meningiomas a slow growth pattern is usually observed. While there are well-known relations between proliferation and tumor grade, ${ }^{20,21}$ different patterns of behavior for intracranial meningiomas under the influence of elevated serum levels of sex hormones (for example, progesterone) during pregnancy have also been reported; tumor growth ${ }^{9}$ and neurological improvement due to possible minimal regression ${ }^{4}$ have both been observed. Clear volumetric tumor regression after pregnancy has not
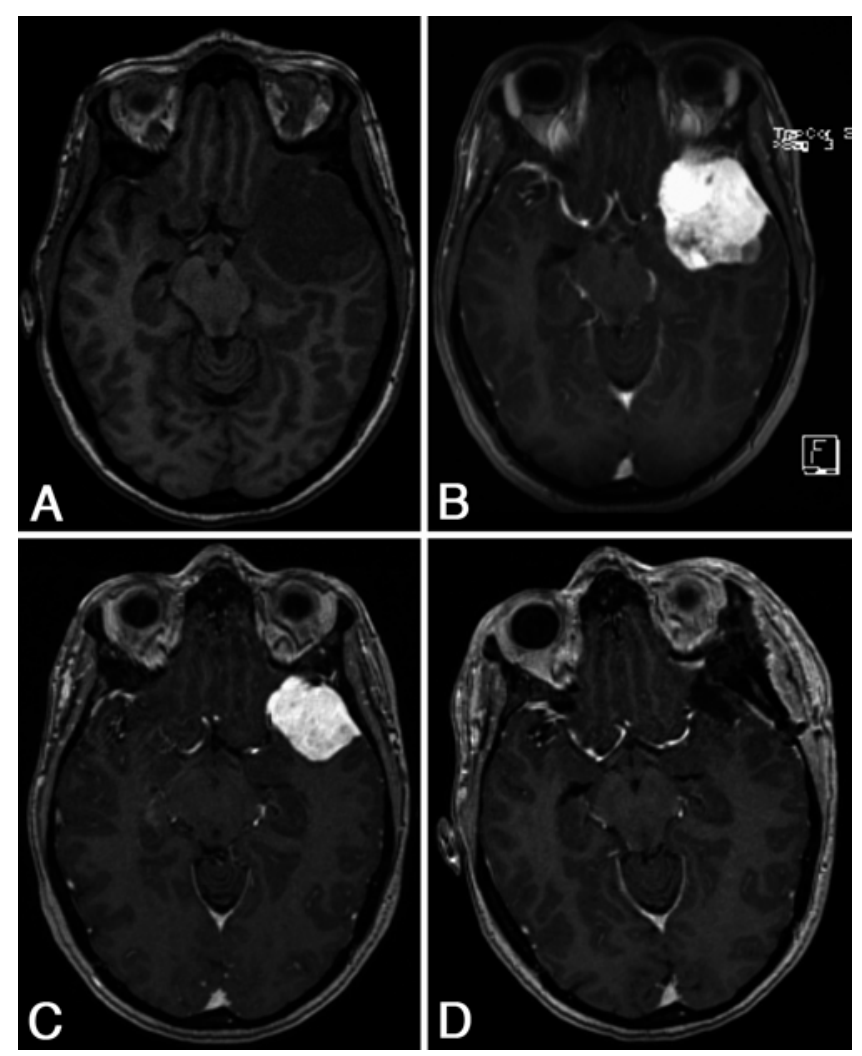

FIG. 1. A: First MR image obtained during pregnancy, showing an extraaxial lesion. B: Axial MR image obtained the 1st day after cesarean section, showing homogeneous $\mathrm{Gd}$ enhancement (lesion volume 53.1 $\mathrm{cm}^{3}$ ). C: Axial MR image obtained 2 months after giving birth, revealing a significant mass reduction (lesion volume $27.6 \mathrm{~cm}^{3}$ ). D: Postoperative MR image showing complete tumor resection.

been documented. Given the meningioma's expression of different hormone receptors for progesterone, androgen, estrogen, and placenta growth factor ${ }^{2,10,11}$ and its response to increased serum levels of sex hormones during pregnancy, rapid tumor growth or the sudden onset of symptoms (for example, headache, double vision), as occurred in the presented case, seems plausible. This may also explain why symptoms might develop for the first time during the course of a pregnancy. After delivery significant reduction of the tumor was observed, most likely because it lacked stimulation by a decreased serum progesterone level. The high level of progesterone receptor expression of more than $90 \%$ in the specimen is particularly noteworthy given the numerous studies investigating the role of sex hormones and the over-abundance of such tumors in women., $1,8,28,31$

A small cohort study ${ }^{23}$ revealed a correlation between progesterone receptor status and the biological behavior of tumors; patients with progesterone-positive tumors showed decreased recurrence rates after tumor resection. Furthermore, several case reports dealing with symptomatic meningiomas during pregnancy have been published., ${ }^{3,26} \mathrm{In}$ the presented case, the patient experienced minor symptoms despite the extent of the intracranial mass. The advanced pregnancy and concomitant low risk in delivering the fetus just days before reaching full term facilitated the decision-making toward cesarean delivery. Postpartum, 


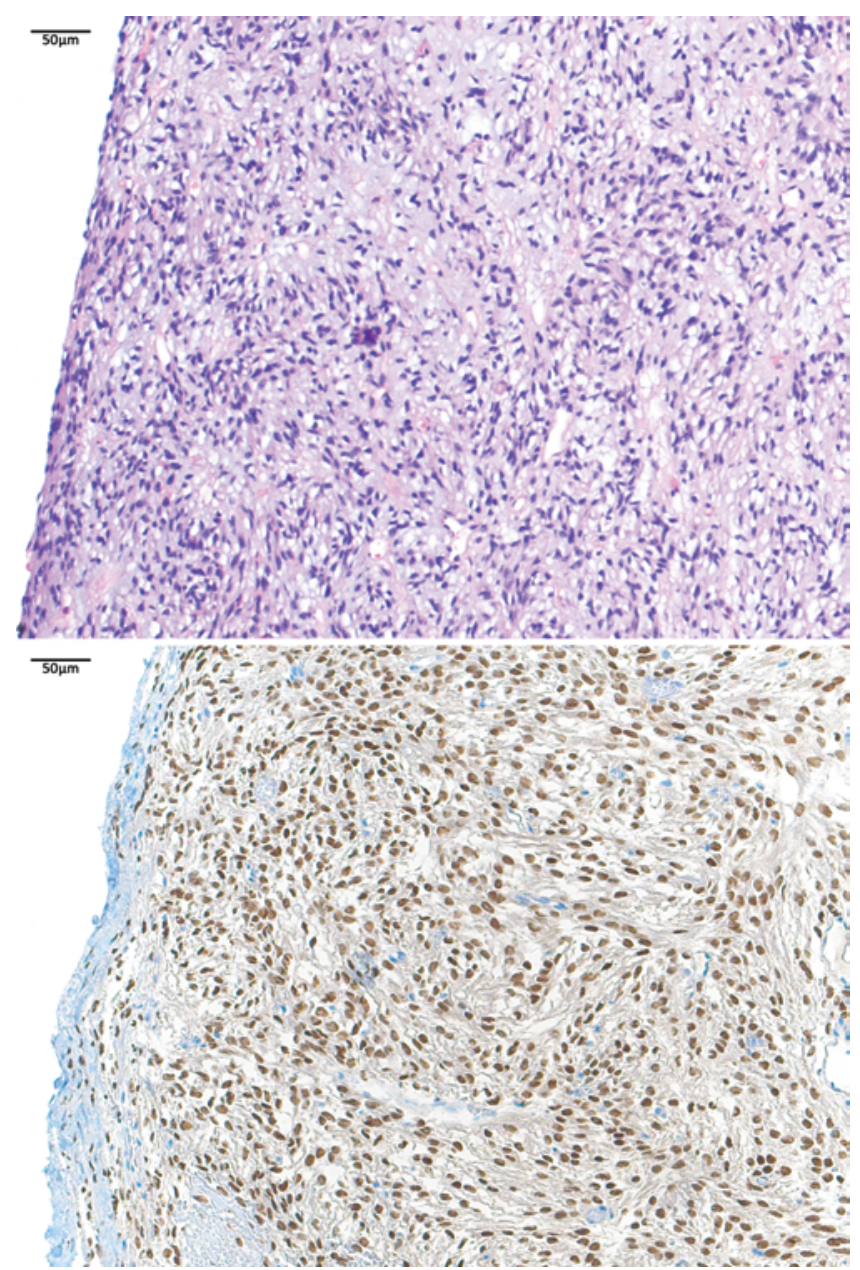

FIG. 2. Photomicrographs with antibody against the progesterone receptor showing strong nuclear immunoreactivity in nearly all tumor cells. $\mathrm{H}$ \& $\mathrm{E}$ (upper). Figure is available in color online only.

the low-dose steroids could be tapered until the resection, resulting in elective surgery under controlled conditions for the patient, her family, and the treating physicians. Contrast-enhanced MRI was conducted just after delivery because there is a general recommendation against the use of $\mathrm{Gd}$ in pregnant women. A potential risk especially for the unborn includes nephrogenic systemic fibrosis because of immature renal function. Furthermore, Gd retention in the tissue with less stable agents and the lack of knowledge regarding its long-term effects are causes for concern, restricting use in neonates. ${ }^{29}$ The same precaution seems reasonable in pregnant women. This compels postponement of elective surgery in patients with minor symptoms until after the first vulnerable postpartum months, which provides the opportunity for the augmented risks of thromboembolic events such as pulmonary embolism, deep vein thrombosis, or coagulopathy disorders after birth to become normal. ${ }^{12,24}$ Furthermore, emotional components such as postpartum depression that could be aggravated after brain surgery may stabilize, leading to a better outcome. It seems reasonable to perform interdisciplinary risk assessments in patients presenting earlier in pregnancy and with symptomatic meningiomas, taking into account possible harm to the unborn and permanent neurological deficits. ${ }^{5}$ Depending on the severity of symptoms and a potential trial of steroids, surgery may often still be indicated.

In cases with minor symptoms and relief with low-dose steroids following cesarean section, this strategy of delayed elective surgery might be the right choice for women at the end of a pregnancy. Elective surgery postponed for some months if possible leads to a stabilized situation and may also facilitate resection due to a reduced tumor size in meningiomas highly sensitive to levels of sex hormones.

RU-486, a progesterone receptor antagonist, has been tested in clinical trials with mixed results. Grunberg et al. treated 14 patients, 5 of whom had an objective response and 3 of whom also experienced subjective improvement. ${ }^{13,15}$ In a later series, the same group of investigators described 28 patients treated with the same drug, with a minor response in only 8 patients (all premenopausal). ${ }^{14}$ Immunohistochemical testing was not performed. A recent publication showed favorable results in postmenopausal patients with multiple meningiomas with up to 10 years of follow-up. ${ }^{27}$ Overall, the side effects of long-term RU-486 treatment seem to be minor, so no discontinuation of treatment was necessary in either study. Immunohistochemical progesterone receptor staining was done, although there was no proof of progesterone receptor expression; such staining seems to be mandatory when considering RU-486 treatment. Both of the latter studies showed promising results in patients with a high progesterone receptor density in tumor tissue.

\section{Conclusions}

Meningiomas can be influenced by levels of female sex hormones, leading to accelerated growth during pregnancy. If possible and in cases of only minor symptoms, resection should be conducted after delivery. To our knowledge, the presented case shows, for the first time, that delaying surgery for some months after delivery may result in easier resection given the possible shrinkage of hormonesensitive meningiomas. In addition, a stabilized condition after pregnancy may be beneficial for those patients.

\section{References}

1. Abdelzaher E, El-Gendi SM, Yehya A, Gowil AG: Recurrence of benign meningiomas: predictive value of proliferative index, BCL2, p53, hormonal receptors and HER2 expression. Br J Neurosurg 25:707-713, 2011

2. Carroll RS, Zhang J, Black PM: Expression of estrogen receptors alpha and beta in human meningiomas. J Neurooncol 42:109-116, 1999

3. Cardenas-Goicoechea SJ, Debbs RH: Meningioma during pregnancy: a case report. J Reprod Med 56:81-84, 2011

4. Chacko JG, Miller JL, Angtuaco EJ: Spontaneous postpartum resolution of vision loss caused by a progesterone receptor-positive tuberculum sellae meningioma. J Neuroophthalmol 30:132-134, 2010

5. Chowdhury T, Chowdhury M, Schaller B, Cappellani RB, Daya J: Perioperative considerations for neurosurgical procedures in the gravid patient: Continuing Professional Development. Can J Anaesth 60:1139-1155, 2013

6. Claus EB, Bondy ML, Schildkraut JM, Wiemels JL, Wrensch M, Black PM: Epidemiology of intracranial meningioma. Neurosurgery 57:1088-1095, 2005 
7. Cowppli-Bony A, Bouvier G, Rué M, Loiseau H, Vital A, Lebailly P, et al: Brain tumors and hormonal factors: review of the epidemiological literature. Cancer Causes Control 22:697-714, 2011

8. Custer B, Longstreth WT Jr, Phillips LE, Koepsell TD, Van Belle G: Hormonal exposures and the risk of intracranial meningioma in women: a population-based case-control study. BMC Cancer 6:152, 2006

9. DeGrood RM, Beemer WH, Fenner DE, Compton AA: A large meningioma presenting as a neurologic emergency in late pregnancy. Obstet Gynecol 69:439-440, 1987

10. Donnell MS, Meyer GA, Donegan WL: Estrogen-receptor protein in intracranial meningiomas. J Neurosurg 50:499_ 502,1979

11. Donnini S, Machein MR, Plate KH, Weich HA: Expression and localization of placenta growth factor and PIGF receptors in human meningiomas. J Pathol 189:66-71, 1999

12. Fardiazar Z, Hajizadeh K, Dinparvar S, Esmaili F: Thromboembolism and thrombosis during pregnancy and after delivery between 2009 and 2012 in Al-Zahra Educational Center. J Caring Sci 3:221-226, 2014

13. Grunberg SM: The role of progesterone receptors in meningioma. Cancer Treat Res 58:127-137, 1991

14. Grunberg SM, Weiss MH, Russell CA, Spitz IM, Ahmadi J, Sadun A, et al: Long-term administration of mifepristone (RU486): clinical tolerance during extended treatment of meningioma. Cancer Invest 24:727-733, 2006

15. Grunberg SM, Weiss MH, Spitz IM, Ahmadi J, Sadun A, Russell CA, et al: Treatment of unresectable meningiomas with the antiprogesterone agent mifepristone. J Neurosurg 74:861-866, 1991

16. Idowu OE, Shokunbi MT, Amanor-Boadu SD, Roberts OA, Eyo C: Surgical management of tuberculum sellae meningioma in a patient with a twin pregnancy: case report. Surg Neurol 62:60-63, 2004

17. Ismail K, Coakham HB, Walters FJ: Intracranial meningioma with progesterone positive receptors presenting in late pregnancy. Eur J Anaesthesiol 15:106-109, 1998

18. Kanaan I, Jallu A, Kanaan H: Management strategy for meningioma in pregnancy: a clinical study. Skull Base 13:197203, 2003

19. Kasper EM, Hess PE, Silasi M, Lim KH, Gray J, Reddy H, et al: A pregnant female with a large intracranial mass: Reviewing the evidence to obtain management guidelines for intracranial meningiomas during pregnancy. Surg Neurol Int 1:95, 2010

20. Louis DN, Ohgaki H, Wiestler OD, Cavenee WK, Burger PC, Jouvet A, et al: The 2007 WHO classification of tumours of the central nervous system. Acta Neuropathol 114:97-109, 2007

21. Maier H, Wanschitz J, Sedivy R, Rössler K, Ofner D, Budka $\mathrm{H}$ : Proliferation and DNA fragmentation in meningioma subtypes. Neuropathol Appl Neurobiol 23:496-506, 1997

22. Michaud DS, Gallo V, Schlehofer B, Tjønneland A, Olsen A, Overvad K, et al: Reproductive factors and exogenous hormone use in relation to risk of glioma and meningioma in a large European cohort study. Cancer Epidemiol Biomarkers Prev 19:2562-2569, 2010

23. Mukherjee S, Ghosh SN, Chatterjee U, Chatterjee S: Detection of progesterone receptor and the correlation with Ki-67 labeling index in meningiomas. Neurol India 59:817-822, 2011

24. Pfanner G, Kilgert K: [Haemorrhagic complications in obstetrics.] Hamostaseologie 26 (3 Suppl 1):S56-S63, 2006 (Ger)

25. Sahu S, Lata I, Gupta D: Management of pregnant female with meningioma for craniotomy. J Neurosci Rural Pract 1:35-37, 2010

26. Shitara S, Nitta N, Fukami T, Nozaki K: Tuberculum sellae meningioma causing progressive visual impairment during pregnancy. Case report. Neurol Med Chir (Tokyo) 52:607611,2012

27. Touat M, Lombardi G, Farina P, Kalamarides M, Sanson M: Successful treatment of multiple intracranial meningiomas with the antiprogesterone receptor agent mifepristone (RU486). Acta Neurochir (Wien) 156:1831-1835, 2014

28. Vadivelu S, Sharer L, Schulder M: Regression of multiple intracranial meningiomas after cessation of long-term progesterone agonist therapy. J Neurosurg 112:920-924, 2010

29. Webb JA, Thomsen HS: Gadolinium contrast media during pregnancy and lactation. Acta Radiol 54:599-600, 2013

30. Wigertz A, Lönn S, Hall P, Auvinen A, Christensen HC, Johansen $\mathrm{C}$, et al: Reproductive factors and risk of meningioma and glioma. Cancer Epidemiol Biomarkers Prev 17:26632670,2008

31. Wolfsberger S, Doostkam S, Boecher-Schwarz HG, Roessler K, van Trotsenburg M, Hainfellner JA, et al: Progesteronereceptor index in meningiomas: correlation with clinicopathological parameters and review of the literature. Neurosurg Rev 27:238-245, 2004

32. Zak IT, Dulai HS, Kish KK: Imaging of neurologic disorders associated with pregnancy and the postpartum period. Radiographics 27:95-108, 2007

\section{Author Contributions}

Conception and design: Kerschbaumer, Thomé, Seiz-Rosenhagen. Acquisition of data: Kerschbaumer, Freyschlag, Stockhammer, Maier, Seiz-Rosenhagen. Analysis and interpretation of data: Thomé, Seiz-Rosenhagen. Drafting the article: SeizRosenhagen. Critically revising the article: all authors. Reviewed submitted version of manuscript: Kerschbaumer, Freyschlag, Taucher, Thomé, Seiz-Rosenhagen. Approved the final version of the manuscript on behalf of all authors: Kerschbaumer.

\section{Correspondence}

Johannes Kerschbaumer, Department of Neurosurgery, Medical University of Innsbruck, Anichstrasse 35, 6020 Innsbruck, Austria.email: johannes.kerschbaumer@uki.at. 